\title{
Double-difference relocations of the 2004 off the Kii peninsula earthquakes
}

\author{
Bogdan Enescu ${ }^{1}$, James Mori ${ }^{1}$, and Shiro Ohmi ${ }^{1}$ \\ ${ }^{1}$ Disaster Prevention Research Institute (DPRI), Kyoto University, Gokasho, Uji, Kyoto, 611-0011, Japan
}

(Received November 25, 2004; Revised March 23, 2005; Accepted April 8, 2005)

\begin{abstract}
Two large earthquakes (Mw7.3 and Mw7.5) occurred off-shore of the Kii peninsula (Japan) on 5th September 2004. The insufficient station coverage in the area where the large events and their aftershocks occurred led to significant uncertainty regarding their depth location. By using a double-difference approach, we were able to determine more accurate hypocenter locations and better define the main characteristics of the aftershock distribution. The data we used in this study comprise of about 700 earthquakes recorded by the Japanese Meteorological Agency (JMA) from 5 to 12 September 2004. We assume several depth ranges for the initial double difference earthquake locations and select the solution with the smallest rms residual. The resulting hypocenter distribution has two distinctive features: 1) on average the depths are about $20 \mathrm{~km}$ shallower than the initial JMA location and 2) the hypocenters are divided into two groups: one shallow (around $12 \mathrm{~km} \mathrm{depth}$ ) and another deep (around $27 \mathrm{~km}$ depth). The epicenters of the relocated events define a finer, more clustered structure compared with the epicentral distribution of JMA. The splitting of the earthquake locations into two depth groups is still observed when using a significantly different velocity structure. Our results of the two depth groups for the hypocenters resemble the independently determined hypocentral distribution from the $O B S$ survey.
\end{abstract}

Key words: Off the Kii peninsula earthquakes, double-difference relocation.

\section{Introduction}

Due to the dense distribution of seismic stations for the onshore areas of Japan, the earthquakes that occur in these regions have relatively accurate hypocenter locations (e.g. Ueno et al., 2002). The recent development of the doubledifference algorithm (Waldhauser and Ellsworth, 2000) makes it possible to further refine the event locations and characterise the detailed structure of seismicity. We demonstrate in this work that by carefully applying the above mentioned algorithm it is also possible to improve the locations of earthquakes that occur in off-shore regions that have relatively poor coverage of seismic stations. The purpose of this letter is to show that for the aftershocks of 2004 off the Kii Peninsula earthquakes, using mostly the onshore stations, we can obtain a hypocentral distribution that resembles the results from the later Ocean Bottom Seismograph $(O B S)$ survey (Shinohara et al., 2004b) that was carried out in this region.

\section{Data and Method of Analysis}

The data used in this study consist of about 700 aftershocks that occurred from 5 to 12 Sept. 2004 off-shore of the Kii Peninsula. The earthquakes (Fig. 1(a)) were recorded and located by the Japan Meteorological Agency $(J M A)$, using a single-event location method. We use about $40,000 P$ and $S$ arrival times at 40 seismic stations, as shown in the inset of Fig. 1(a). The lack of stations close to the epicentral area, combined with their rather unfavourable

Copy right(C) The Society of Geomagnetism and Earth, Planetary and Space Sciences (SGEPSS); The Seismological Society of Japan; The Volcanological Society of Japan; The Geodetic Society of Japan; The Japanese Society for Planetary Sciences; TERRAPUB distribution, made it difficult to determine accurately the depth location of the events. Most stations are generally situated at distances between 80 to $200 \mathrm{~km}$ from the relocated events, while their azimuthal gap is between $190^{\circ}$ to $260^{\circ}$. There are also four permanent $O B S$ (ocean-bottom seismometers), which recorded the earthquakes, the closest one situated at a distance of about $80 \mathrm{~km}$ from the epicenters. By examining the waveforms of aftershocks recorded at several seismic stations, we noticed generally a clear onset of both $P$ and $S$-wave arrival times. We are thus confident that the arrival times used for the relocations are reliable and the picking errors are generally small.

The relocation of earthquakes is done by using the double-difference algorithm (Waldhauser and Ellsworth, 2000). The method minimizes the residuals between observed and theoretical travel-time differences (or doubledifferences) for pairs of earthquakes at each seismic station while linking together all observed event-station pairs. A least-squares solution is found by iteratively adjusting the vector difference between hypocentral pairs.

Because of the uncertainty of the depth location of earthquakes, we followed an approach where the aftershocks were relocated by assuming various depths for the initial locations. The initial depths were obtained by subtracting from the $J M A$ determined depths $0,5,10,15,20$ and $25 \mathrm{~km}$. For each relocated event we selected the solution with the smallest $r m s$ residual among the five trial depths. As generally known for earthquake locations, the starting depth can affect the results, since solutions can fall into local minima close to the trial depth. For this reason, we use a range of trial depths and choose the solution that produces the smallest $r m s$ residual compared to the 1-D model. Trial depths 

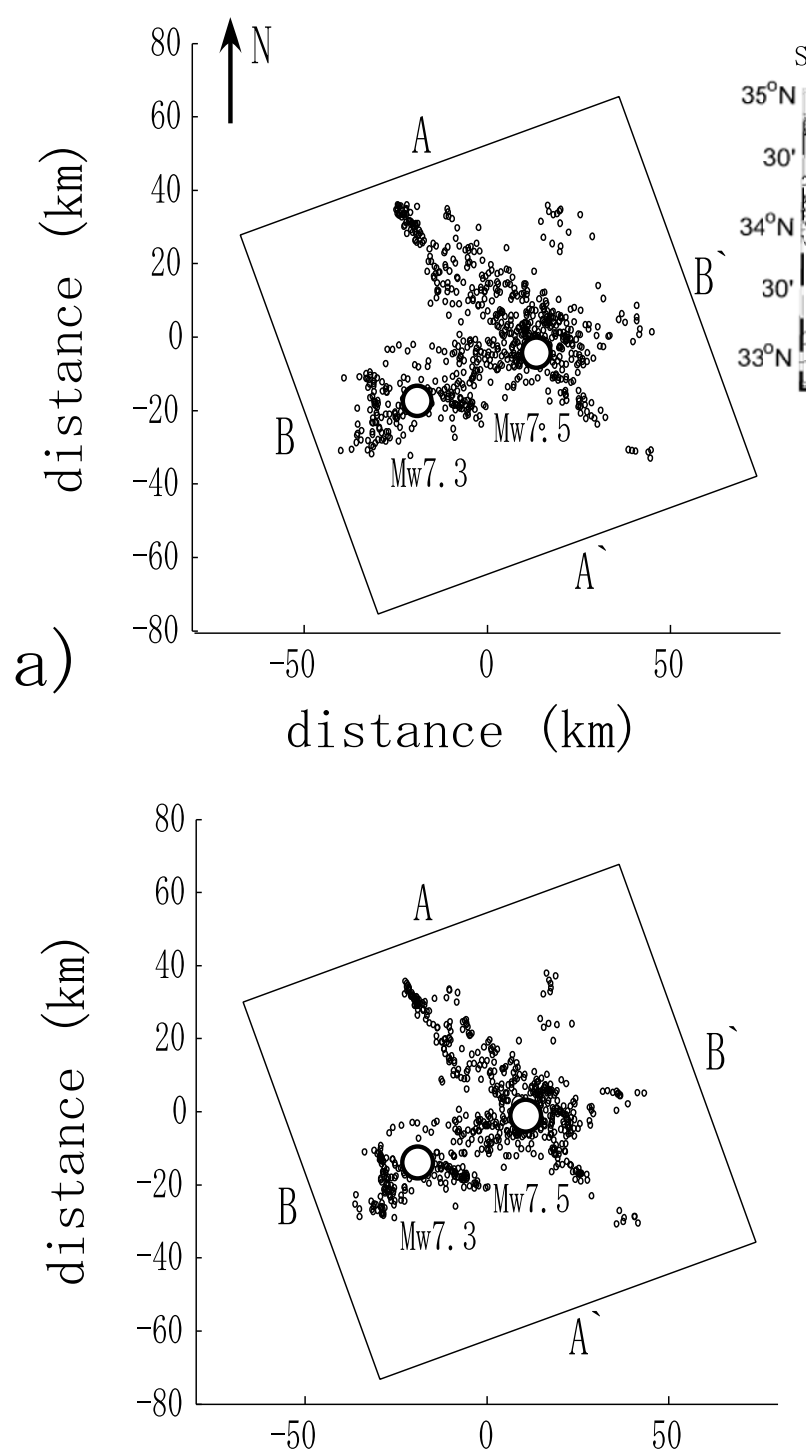

b)
Station \& Epicenter Map

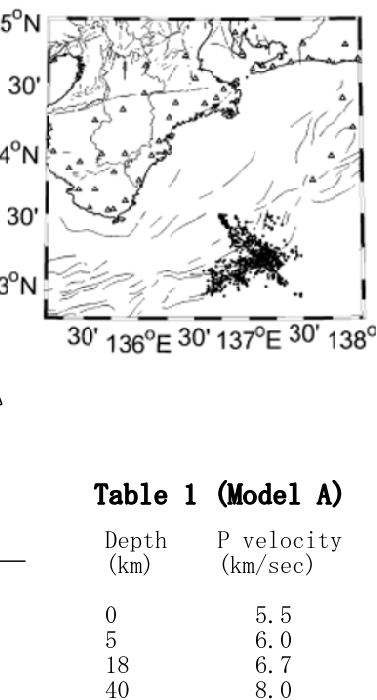

Table 2 (Model B)

$\begin{array}{lc}\begin{array}{c}\text { Depth } \\ (\mathrm{km})\end{array} & \begin{array}{c}\text { P velocity } \\ (\mathrm{km} / \mathrm{sec})\end{array} \\ 0 & 3.0 \\ 10 & 5.6 \\ 15 & 6.9 \\ 20 & 7.5 \\ 30 & 7.8\end{array}$

Fig. 1. Epicentral distribution of the Kii peninsula events: a) determined by $J M A$, b) final results of the double-difference relocation. Inset shows the distribution of seismic stations (triangles). Coastlines are represented by thick lines, while internal borders and faults are shown by thin lines. The large circles in both figures show the epicenters of the major events (Mw7.3, Mw7.5). $\mathrm{AA}^{\prime}$ and $\mathrm{BB}^{\prime}$ indicate the directions of projections that are used in the following figures. Table 1: Kyoto University velocity structure used to relocate earthquakes (Model A). Table 2: Velocity structure derived from Nakanishi et al. (2002) to relocate earthquakes in Figs. 4(c) and (d) (Model B). We assumed a $V p / V s$ ratio of 1.73.

were tested for a range of values from 0 to $25 \mathrm{~km}$ shallower than the JMA depth, which correspond to actual trial depths of about 5 to $50 \mathrm{~km}$.

While the earthquakes occurred in a rather complex 3D structure, we consider a $1 \mathrm{D}$ velocity model to be sufficient since the subducting slab in this region of the Nankai Trough, where the Kii Peninsula events have occurred, dips at a shallow angle (see Nakanishi et al., 2002). The velocity model (Table 1 in Fig. 1) adopted in this study is the one used by DPRI, Kyoto University (Maeda and Watanabe, 1984) to routinely locate earthquakes in the region. The pattern of the hypocenter relocations, however, does not change greatly if a different $1 \mathrm{D}$ velocity structure is assumed (more details are given in Section 3), although the absolute depth changes.

\section{Results and Discussion}

Figure 1(a) presents the epicentral map of the Kii peninsula earthquakes located by JMA. By applying the doubledifference relocation as described in Section 2, we obtained a similar pattern for the epicentre distribution for all of the trial depths. Figure 1(b) shows the map of epicenters obtained after selecting for each event the location with the smallest rms residual. The epicentral distribution of the relocated earthquakes looks sharper than that of the original $J M A$ catalogue. There are clear clusters and several lineations. Although a sharper issue does not necessarily mean that the locations are improved, it does seem to suggest that some of the random errors in the locations have been reduced.

Figure 2 shows a NW-SE cross-section of hypocenters located by JMA along with the results of our double- 


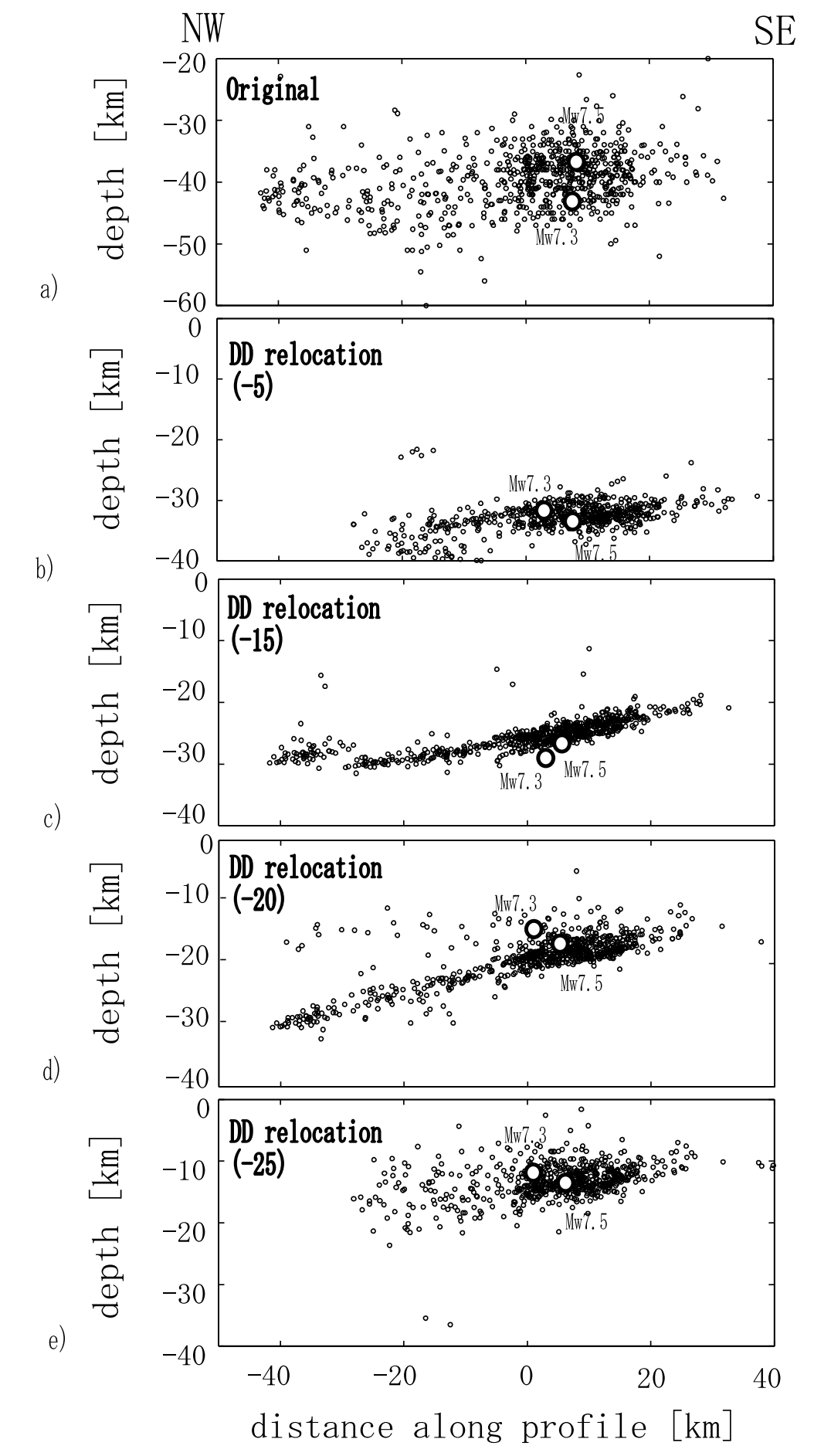

Fig. 2. Hypocentral distribution (JMA) of the Kii peninsula earthquakes. b-e) Results of the double-difference relocation for different initially-assumed depth ranges. The number in parentheses shown in the plots indicates the difference between the depth estimated by $J M A$ and the depth of the initial locations. The direction of projection is NW-SE (AA' in Fig. 1). Epicenters of major events (Mw7.3, Mw7.5) are shown by large circles.

difference relocation for the various initial depths. We also tried to relocate the events by assuming an initial depth range deeper than $40 \mathrm{~km}$, however, the inversion for the hypocenter locations were very unstable and produced inconsistent results. In Fig. 2, the hypocentral distribution, after relocation, is more compact and shows a shallow dip to the northwest. The smallest average $\mathrm{rms}$ residual, of 0.08 $\mathrm{s}$, was obtained if we assume an initial depth of the events at around $20 \mathrm{~km}$ (Fig. 2(d)). The average $r m s$ residual obtained for the other solutions is larger, in particular for cases that assume deeper initial hypocenters. For example, if one considers the hypocenters located at less than $30 \mathrm{~km}$ depth (Fig. 2(b)), the rms residual is of $0.15 \mathrm{~s}$. Picking of the arrivals generally has an uncertainty of about 0.02 to $0.05 \mathrm{~s}$.

When very shallow initial locations are assumed, case (b) of Fig. 2, a relatively small number of events are deleted after relocation, as they have negative depths. By plotting histograms of rms residuals for all events and for all runs (Fig. 3), we detected a bimodal distribution, which suggested that there might be two groups of events with differ- 


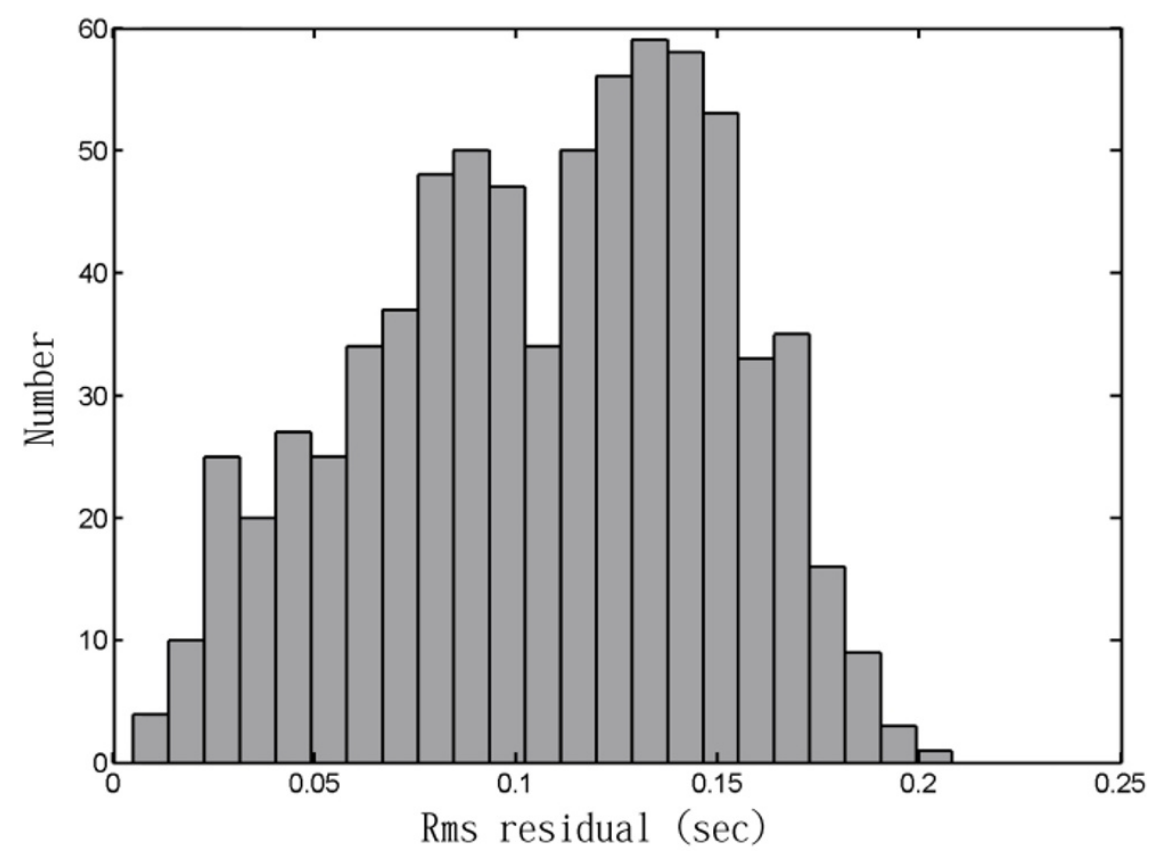

Fig. 3. Histogram of $r m s$ residual for case d) of Fig. 2.

ent depth locations. To verify our speculation, we decided to compare all solutions and choose the location that had the lowest $r m s$ residual, as described in Section 2.

Figures 4(a) and (b) show cross sections of the final distribution of aftershock hypocenters, obtained following the selection procedure described in the previous section. There is a clear split with depth of the aftershock population into an upper and a lower cluster. Also, the relocated events are significantly shallower than those estimated by JMA. Often for off-shore regions, earthquake locations determined mainly from onshore stations by JMA are deeper than locations determined from OBS surveys (e.g. Shinohara et al., 2004a). The depth of the two groups of earthquakes suggest that the first one may have occurred within the subducting oceanic slab, while the second occurred in the uppermost mantle. The depth locations of the major events have probably a larger degree of uncertainty, due to fewer (and probably less reliable) $S$-wave picks. As one can notice in Figs. 2(b), (c), (d) and (e), the relocated events show a more or less clear dipping trend towards NW. However, after selecting for each event the location with the smallest $r m s$, the dip becomes less clear (Fig. 4(a)). While a very shallow dip might be a real feature, we speculate that it is probably an artefact, partly eliminated after selecting the best location for each event.

For epicentral distances larger than about $100 \mathrm{~km}$, it is sometimes possible to observe refracted $P n$ phases as first arrivals. Picking such phases instead of direct $P g$ arrivals would probably bias the relocation results, and can especially be a problem at the cross-over distance. However, it is unlikely that such a bias would favour shallower hypocenters for all the relocated earthquakes. The recent results obtained by using temporary $O B S$ instruments deployed directly above the aftershock region (Shinohara et al., 2004b; Sakai et al., 2005) show clearly that the hypocenters are shallow and this is certainly not an artefact of using re- fracted phases for the relocations. Moreover, the $O B S$ results confirm the splitting of the aftershock distribution into two depth groups. Nakanishi et al. (2002) produced a detailed velocity model for the eastern Nankai Trough, as a result of an extensive seismic refraction and wide-angle reflection survey in the region. Based on their results, we obtained an average 1D velocity structure (Fig. 1: Table 2) and also used it to relocate the Kii peninsula events. By using the same procedure described in Section 2, we found the best location for each event, based on the rms residual. We observe again (Figs. 4(c) and (d)) the splitting of the aftershock distribution into a shallower and a deeper cluster. The two groups are even shallower than before (especially the deeper earthquake cluster becomes shallower), and the relative distance between them is less. This result demonstrates that the splitting of the hypocentral distribution into two depth groups for the Kii peninsula earthquakes does not dependent on the velocity model. One main difference between the first and the second 1D-velocity structures is that the $P$-wave velocity in the region of the earthquakes is faster for the model derived from Nakanishi et al. (2002). The faster velocity results in a closer separation between the two depth groups (Figs. 4(c) and (d)).

For the results shown in Figs. 4(c) and (d), using the velocity derived from Nakanishi et al. (2002), we no longer see the slight dip toward the northwest in the hypocenter distribution. That dip seen in Fig. 2, may be due to the simplified (1D) velocity model used for the double-difference relocations. The velocity structure used for Figs. 4(c) and (d) is probably more appropriate for the earthquakes source region, while the structure used for Figs. 4(a) and (b) is more appropriate for the region of the stations. When using the double-difference algorithm with a 1D structure, it is not clear which of these two structures is more appropriate. 

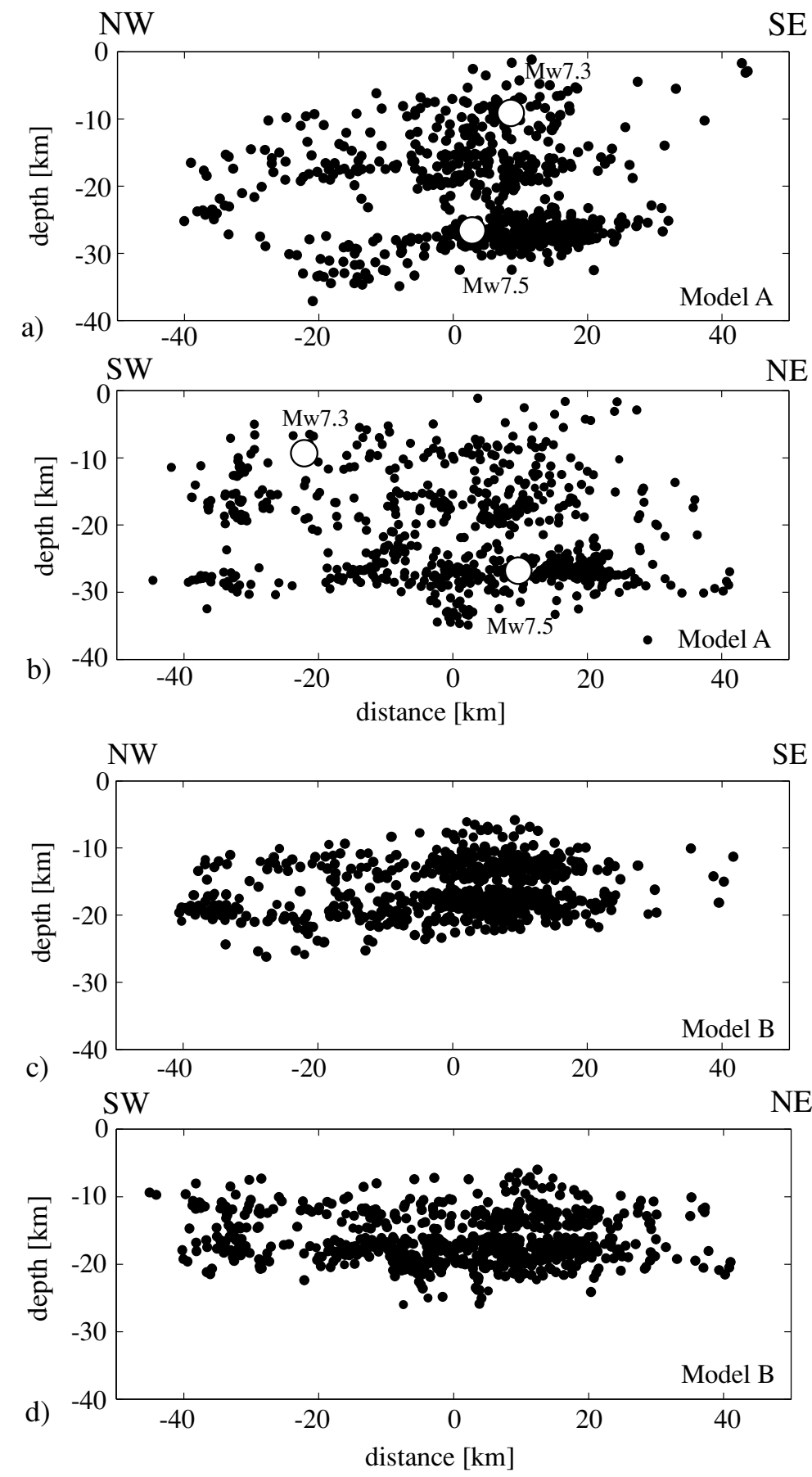

Fig. 4. Final hypocenter distribution of the Kii peninsula events: a) NW-SE (AA' direction) and b) SW-NE (BB' direction) cross-section plots, obtained by using velocity model A (see Fig. 1: Table 1). Large circles show the epicenters of the major events (Mw7.3, Mw7.5). c) NW-SE and d) SW-NE cross-section plots, obtained by using velocity model B (see Fig. 1: Table 2).

\section{Conclusions}

1. By applying the double-difference relocation technique, we obtained a sharper epicentral distribution of the Kii peninsula earthquakes. The depths of the relocated events are on average about $20 \mathrm{~km}$ shallower than the original $J M A$ estimation.

2. The relocated events are split into two clusters: one is shallow (around $12 \mathrm{~km}$ depth) and the other is deeper (around $27 \mathrm{~km}$ depth). The depth of the first group of events may indicate that it occurs within the subducting oceanic slab. The second group occurred probably in the uppermost mantle. Using a significantly different velocity structure, the hypocenters are still seen to separate into two depth groups, similar to the results from the $O B S$ data.

3. The relocation approach proposed in this study may be used successfully to improve the location of events with large depth uncertainty, which occurred in regions with poor station coverage.

Acknowledgments. We thank Prof. Kiyoshi Ito, Prof. Ichiro Kawasaki, Dr. Masatoshi Miyazawa and Ms. Bai Ling for useful discussions. We are grateful to the editor, Prof. Naoshi Hirata, to Dr. Masanao Shinohara and another anonymous reviewer for their 
insightful comments. BE is grateful to the Japanese Society for the Promotion of Science (JSPS) for providing him a fellowship to do research at $D P R I$, Kyoto University.

\section{References}

Maeda, N. and H. Watanabe, Mode of activity of microearthquakes-In the case of the middle and northern parts of Kinki District, southwestern Japan, Zisin, 37, 579-598, 1984 (in Japanese).

Nakanishi, A., H. Shiobara, R. Hino, K. Mochizuki, T. Sato, J. Kasahara,

N. Takahashi, K. Suyehiro, H. Tokuyama, J. Segawa, M. Shinohara, and H. Shimahura, Deep crustal structure of the eastern Nankai Trough and Zenisu Ridge by dense airgun-OBS seismic profiling, Marine Geology, 187, 47-62, 2002.

Sakai, S., T. Yamada, M. Shinohara, H. Hagiwara, T. Kanazawa, K. Obana, S. Kodaira, and Y. Kaneda, Urgent aftershock observation of the 2004 off the Kii Peninsula earthquake using ocean bottom seismometers, Earth, Planets Space, 57, this issue, 363-368, 2005.

Shinohara, M. T. Yamada, T. Kanazawa, T. Hirata, Y. Kaneda, T. Takanami, H. Mikada, K. Suyehiro, S. Sakai, T. Watanabe, K. Uehira, Y. Murai, N. Takahashi, M. Nishino, K. Mochizuki, T. Sato, E. Araki, R.
Hino, K. Uhira, H. Shiobara, H. Shimizu, Aftershock observation of the 2003 Tokachi-oki earthquake by using dense ocean bottom seismometer network, Earth Planets Space, 56, 295-300, 2004a.

Shinohara, M., T. Yamada, S. Sakai, T. Kanazawa, K. Obana, S. Kodaira, M. Kinoshita, and Y. Kaneda, Urgent observation of earthquakes occurred off-coast of the Kii peninsula, by using ocean bottom seismometers, 2004 Meeting of the Seismological Society of Japan, book of abstracts (supplementary pages), 2004b.

Ueno, H., K. Nakamura, S. Aoki, T. Aketagawa, K. Ohtake, A. Kamiya, D. Nozaka, D. Hasebe, O. Kamigaichi, and H. Hamada, The improvement for precise earthquake location determined by Japan Meteorological Agency (Part 3), 2002 Japan Earth and Planetary Joint Meeting, Tokyo, 2002.

Waldhauser, F. and W. L. Ellsworth, A double-difference earthquake location algorithm: method an application to the northern Hayward Fault, California, Bull. Seism. Soc. Am., 80, 1548-1368, 2000.

B. Enescu (e-mail: benescu@eqh.dpri.kyoto-u.ac.jp), J. Mori, and S. Ohmi 